\title{
The Salutogenic Model: The Role of Generalized Resistance Resources
}

\author{
Orly Idan, Monica Eriksson, and Michal Al-Yagon
}

\section{Introduction}

This chapter reviews and integrates conceptual and empirical research focusing on the role of Generalized Resistance Resources (GRRs) within the Salutogenic model. In particular, this chapter discusses findings regarding the conceptual and empirical progress seen in the study of GRRs at the individual, family, and community ecological levels in understanding individual differences in sense of coherence (SOC). Each of the latter attempts to relate to the lifespan in its childhood, adolescent, and adult developmental phases. Specifically, the present chapter uniquely focuses on variables that may contribute to the understanding of individuals' level of SOC within the Salutogenic model, in contrast to previous reviews which focused primarily on SOC's role in understanding individuals' affective functioning, such as well-being, resilience, and coping strategies.

Overall, the term Generalized Resistance Resources (GRR) was coined by Antonovsky (1979, 1987) and comprises the characteristics of a person, a group, or a community that facilitate the individual's abilities to cope effectively with stressors and contribute to the development of the individual's level of (SOC). As proposed by Antonovsky (1987) the GRRs refer to "phenomena that provide one with sets of life experiences characterized by consistency, participation in shaping outcomes and an underload-overload balance" (Antonovsky, 1987, p. 19).

O. Idan $(\bowtie)$

Psychology of Intergroup Conflict and Reconciliation Lab, School of Psychology, Interdisciplinary Center (IDC), Herzliya, Israel e-mail: oidan@idc.ac.il

\section{Eriksson}

Department of Health Science, University West, Trollhattan, Sweden e-mail: monica.eriksson@hv.se

\section{Al-Yagon}

Joan and Jaime Constantiner School of Education, Tel Aviv University, Tel Aviv, Israel

e-mail: alyagon@post.tau.ac.il
According to Antonovsky $(1979,1987)$ such resources may include the following factors (1) material resources (e.g., money), (2) knowledge and intelligence (e.g., knowing the real world and acquiring skills), (3) ego identity (e.g., integrated but flexible self), (4) coping strategies; (5) social support, (6) commitment and cohesion with one's cultural roots, (7) cultural stability, (8) ritualistic activities, (9) religion and philosophy (e.g., stable set of answers to life's perplexities), (10) preventive health orientation, (11) genetic and constitutional GRRS, and (12) individuals' state of mind (see Horsburgh \& Ferguson, 2012 for a review).

In an attempt to develop a more parsimony model, Antonovsky (1987) merged the concept of the GRRs with his earlier concept of the 'stressors' and combined them into one concept-Generalized Resistance Resources-Resistance Deficits (GRR-RDs). Accordingly, each of these GRRs was presented on a continuum. Thus, an individual who is higher on the continuum tends to have consistent, balanced life experiences and high participation in decision making. In contrast, an individual who is lower on the continuum tends to have inconsistent, low balanced life experiences and low participation in decision making. In line with these assumptions, among individuals who are higher on the continuum the GRR-RDs are viewed as GRRs and among individuals who are lower on the continuum the GRR-RDs are viewed as GRDs. Based on these assumptions, both GRRs and GRDs (Generalized Resistance Deficits) contribute to the development of an individual's SOC.

Importantly, although the salutogenic model presumes that individuals develop strong SOC through successful applications of GRR-RDs across the lifespan, this model also proposed a reciprocal and dynamic relationship between SOC and GRR-RDs. Thus, GRR-RDs may contribute to an individual's level of SOC and an individual's level of SOC may contribute to mobilize GRRs for enhancing of tension management. However, as suggested by Antonovsky (1987), when GRRs or GRDs may became chronic and built into the 
life situation of the person, they are viewed as the primary determinants of the strength of an individual's level of SOC.

In general, the initial GRR resources (Antonovsky, 1979) may be perceived as manifested within the life experiences as proposed by Antonovsky (1991). Thus, three types of life experiences assumed to contribute to the SOC developmental process: consistency, load balance, and participation in shaping outcomes. The fourth dimension-emotional closeness-was added later by Sagy and Antonovsky (2000). The first of these life experiences-consistency-refers to the extent to which, during the course of growing-up, messages were clear and there was order and structure rather than chaos in one's environment. As suggested by Antonovsky (1991), experiences of consistency in an individual's life provide the basis for the comprehensibility component of the SOC. The second life experience-load balance-refers to the extent to which, during the course of growing up, one experienced overload or underload in the balance between the demands made upon one and one's resources. Such load balance is important for the SOC's manageability component. The third life experience-participation in shaping outcomes - refers to the extent to which one had a significant part in deciding her/his fate and was not an object of the power and whims of others. Participation in shaping outcomes provides the basis for the meaningfulness component. Sagy and Antonovsky (1996) selected the mentioned three life experiences in their qualitative analysis of the narratives of two women whose life histories were similar in their historical and social contexts. However, their life orientation as expressed in their stories and their levels of SOC were different (note: to be expanded upon receipt of article). The fourth life experience (Sagy \& Antonovsky, 2000)_emotional closeness_refers to the extent to which one felt consistent emotional bonds and a sense of belonging in social groups of which one was a member. Similar to the participation in shaping outcomes, the emotional closeness resource was assumed as relevant to the meaningfulness component.

\section{Generalized Resistance Resources: The Individual Level}

\section{Emotional Closeness and Attachment Relationships}

As mentioned above, emotional closeness is one of the four types of life experiences assumed to contribute to the SOC developmental process (Sagy \& Antonovsky, 2000). Close emotional relationships with significant others has been conceptualized primarily within the framework of attachment theory (Bowlby, 1973; Grossmann, Grossmann, \& Waters, 2006; Mikulincer \& Shaver, 2007). Overall,
Bowlby's attachment theory (1973; 1982/1969) underscored the role of early interactions with significant others in explaining individual variations in variety of emotional, social, and behavioral adjustment (Cassidy \& Shaver, 2008; Grossmann et al., 2006). To be noted, although this theory focused on early interactions with significant others, studies have pinpointed that attachment theory is a lifespan developmental theory (see Mikulincer \& Shaver, 2007 for a review). Accordingly, researchers have underscored how adults' attachment representations (Bowlby, 1973, 1982/ 1969) contribute to a variety of psychological resources such as coping with distress and affect regulation (Bernier \& Matte-Gagne, 2011; Collins \& Ford, 2010; Mikulincer \& Shaver, 2004, 2007).

Briefly, attachment theory emphasizes that over the course of the first year of life, infants develop a specific and enduring relationship with their primary caretakers (Ainsworth \& Wittig, 1969). Infants' strong tendency to seek proximity to caregivers is the overt manifestation of the inborn attachment behavioral system, which is designed to restore or maintain proximity to supportive others in times of need. Proximity to an available, supportive, and responsive caregiver ("attachment figure") provides the infant with a sense of "secure base," which refers to a set of expectations about others' availability and responsiveness in times of stress. As emphasized by this theory, attachment figures play a central role in the infant's cognitive, social, and emotional development as well as in the development of a sense of self (Bowlby, 1982/1969; Waters \& Cummings, 2000). Children's experiences with attachment figures are internalized into "working models of attachment"-mental representations of significant others and of the self. These result in unique attachment styles, that is, stable patterns of cognitions as well as behaviors that are manifested in other close relationships and social interactions across the lifespan. In accordance with these assumptions, infants of available and supportive attachment figures are more likely to develop a sense of security and trust. In contrast, infants of unavailable, inconsistent, and/or unresponsiveness attachment figures are more likely to perceive the world as unpredictable, threatening, or rejecting.

In examining the relations between patterns of attachment and youngsters' well-adjusting functioning, the vast majority of attachment research studies indicated that securely attached children and adolescents revealed better mental health and functioning and higher levels of psychological well-being, than did children and adolescents with an insecure style (see Allen, 2008 and Grossmann et al., 2006 for a review). Data from such studies also suggested the role of youngsters' attachment relationships with significant others in understanding their level of SOC. For example, Al-Yagon (2010) investigated the possible role of children's attachment with mothers in understanding variance in children's 
SOC in a sample of 205 mother-child dyads: 107 mothers and their children with specific learning disabilities (SLD), and 98 mothers and their typically developing children. Utilizing Structural Equation Modeling (SEM), this study's outcomes indicated that among both groups, children with and without SLD, children's attachment toward the mother significantly explained the variance in the children's SOC. Thus, children who felt more securely attached to the mother revealed a higher SOC level than did children who felt less securely attached to the mother. Similar findings emerged in examining the role of children's attachment with their fathers in explaining their level of SOC (Al-Yagon, 2011). Accordingly, for both groups (children with and without SLD), the variable of children's attachment toward the father significantly explained variance in children's SOC. Children who felt more securely attached to the father revealed a higher SOC than did children who felt less securely attached to the father.

Interestingly, in exploring the differences in the role of attachment with the fathers and the mothers, Al-Yagon (2014a) reported that in the model modified for elementary school children with SLD, a greater number of significant paths emerged between child-mother attachment relationships and internalizing measures than for childfather attachment. Data also showed that attachment with fathers contributed mainly to children's coping resources (i.e., SOC, hope, and effort), whereas attachment with mothers contributed to a broader range of internalizing adjustment measures including not only SOC but also selfreported loneliness and parent-rated internalizing problems. In other words, regarding attachment to fathers, those children with SLD who viewed themselves as more securely attached with the father reported a higher tendency to see the world as comprehensible, manageable, and meaningful (i.e., higher SOC) compared to children with SLD who viewed themselves as less securely attached.

The role of attachment relationships with significant others in understanding SOC has been less examined among adolescents and adults. However, such studies indicated similar findings to those reported for younger children. For example, in examining three groups of Chinese American college students, Ying, Lee, and Tsai (2007) highlighted the important role of close attachment relationships with both parents and peers in explaining these individuals' development of SOC. Specifically, this study's outcomes yielded that for the groups of early and late Chinese immigrants, both parent and peer attachment enhanced their level of SOC. Thus, these college students' ability to comprehend, manage, and find meaning in their world was contributed both by their parents who may have served as an anchor in their cross-cultural transition, and their peers who facilitated an understanding and mastery of the American environment. As suggested by Ying and his colleagues (2007), such close relationships may be of particular importance for these college students due to the Chinese cultural values of stigma and privacy, which may reduce their likelihood to utilize campus mental health services.

Likewise, attachment studies on adults also highlighted the contribution of adults' attachment to their level of SOC, For instance, Mikulincer and Shaver (2005) reported that lower scores on attachment anxiety and avoidance (i.e., higher levels of attachment security) were associated with higher levels of meaning and SOC in life. In addition, in examining the role of adults' anxiety and avoidance attachment in exploring differences in SOC among parents of children with and without LD, Al-Yagon (2014b) highlighted the potential role of parents' own attachment anxiety for explaining their coping strategies. Specifically, for fathers from the two populations studied, a high level of anxiety in close attachment relationships, as reflected by a hyperactivation of negative emotions and rumination on distress-related thoughts (Mikulincer \& Shaver, 2004), significantly contributed to fathers' low SOC. Similar findings emerged for mothers of children with SLD and for mothers of children with typical development, indicating that a high level of anxiety in attachment relationships significantly contributed to these mothers' low SOC. This study also underscored the role of parental high level avoidant attachment, as reflected by a lower tendency to adopt attachmentdeactivating strategies (Mikulincer \& Shaver, 2004) in contributing to parents' high SOC.

Along with attachment framework, studies have also utilized a variety of other measures to explore the role of emotional closeness in understanding differences in the individual's level of SOC. For example, in investigating the role of parent-child relationships in adolescents' SOC, García-Moya, Moreno, and Jiménez-Iglesias (2013) and García-Moya, Rivera, Moreno, Lindström \& JiménezIglesias (2012) indicated that the quality of parent-child relationships (i.e., perceived affection, ease of communication with parents, parental knowledge, and satisfaction with family relationships) emerged as the main predictors of adolescents' (aged 13-19) level of SOC. Focused on adulthood, findings from Volanen, Lahelma, Silventoinen, and Suominen (2004) suggested that for both men and women the quality of a close relationship with their spouse, significantly contributed to their level of SOC. Thus, an individual's poor close relationship with a partner was a major threat in predicting their level of SOC. Furthermore, a recent study (Daoud, Polsky-Berger, Abu-Kaf, \& Sagy, 2015) on styles of marriage (polygamous versus monogamous) as predictors of SOC found that Bedouin women in polygamous marriages demonstrated higher levels of SOC than women in monogamous marriages, when controlling 
for socioeconomic factors, sociodemographic factors, and social support.

Taken together, these findings suggested that the patterns of attachment relationships and the quality of close relationships with significant others contributed to variation in individuals' coping resources and abilities (i.e., SOC), across the lifespan (see Mikulincer \& Shaver, 2007 for a review). Accordingly, these outcomes highlighted that securely attached individuals appraised themselves as able to cope effectively with stressors, whereas individuals with insecure attachment manifested deficiency in these coping resources. Furthermore, as assumed by attachment researchers, patterns of secure attachment and high qualities of emotional closeness may enhance support-seeking in constructive and effective ways, whereas patterns of insecure attachment and low qualities of emotional closeness may increase inhibition or interference with effective support-seeking (Florian, Mikulincer, \& Bucholtz, 1995; Seiffge-Krenke \& Beyers, 2005).

\section{Personal Characteristics and Resources}

Studies have also explored the possible role of the individual's characteristics and resources in facilitating his/her level of SOC. For example, Volanen et al. (2004) examined the effect of childhood living conditions on SOC levels among men and women aged 25-64. Specifically, childhood living conditions comprised family long-lasting economic difficulties, alcohol problems of the family's member, individual's feeling of fear from some family member, and family's conflicts. Outcomes from this study reported that childhood living conditions showed a strong association with men and women's SOC. As suggested by those researchers, poor childhood living conditions may affect adult SOC in various ways such as the negative impact on self-esteem and positive life attitudes that may contribute to low levels of SOC.

Studies have also explored the role of another demographic feature-the marital status-in understanding SOC. For instance, Read, Aunola, Feldt, Leinonen, and Ruoppila (2005) examined a sample of Finnish participants aged 65-69 years. Outcomes from their study yielded that for men, unlike women, marital status has an important impact as a GRR. Accordingly, for men being married or cohabiting was positively associated with SOC and, SOC in turn contributed to physical, social, and psychological health. As suggested by these researchers, marriage may enhance health in several ways such as influencing the physical and psychosocial environment in which the individual lives. These results were similar to those reported by several other studies demonstrating the beneficial effect of marriage in buffering against morbidity and mortality, especially for men (see Read, Aunola, Feldt, Leinonen, \&
Ruoppila, 2005 for a review). Several explanations were proposed regarding these results, such as the possibility that men may profit more than women from marriage as a GRR because healthy lifestyle and behaviors are more encouraged by wives than husbands, due to the women's tendency to value health more than men (Read et al., 2005).

In these contexts of personal characteristics and resources, Al-Yagon (2014b) explored the role of parents' emotional resources (attachment anxiety/avoidance and negative/positive affect) in explaining differences in their coping resources (child-related active/avoidant coping and SOC). Focused on parental emotional resources in understanding their SOC, this study highlighted the potential role of parents' positive and negative affect in explaining their SOC, especially among parents of children with SLD, and more so for mothers of children with SLD than for fathers. Specifically, higher levels of positive affect such as feelings of "energetic" or "happy" significantly contributed to parents' higher SOC levels for both groups of fathers and mothers of children with SLD. In contrast, higher negative affect such as feelings of "anxious," "tense," "agitated," or "worried" significantly contributed to lower levels of parental SOC across the board.

In accordance with these outcomes, a high level of negative parental affect was a major risk factor for lower SOC and a high level of positive affect was a major protective factor for higher SOC. This study suggested several directions for interventions, such as teaching parents to become more attuned to their own emotional functioning, learn how their feelings influence parenting, and learn strategies to regulate emotions (Al-Yagon, 2014b).

Of particular importance studies of personal characteristics and resources among individuals in the "third age" emphasize the contribution of psychological resources on SOC. Wiesmann and Hannoch (2011) examined salutogenic predictors of multiple health behaviors in a sample of healthy "third age" individuals and, in accordance with Antonovsky's (1987) hypothesis found that meaningfulness was the most distinguishing among the SOC components. Moreover, the aging individuals reported that their lives made sense and were worthy of commitment and engagement. SOC components were significantly associated with multiple health behaviors and were also significantly interrelated. In accordance with the salutogenic theory, the strong correlations among the components explained their overlapping and yet distinct character. Furthermore, meaningfulness mediated self-esteem and self-efficacy influences on multiple health behaviors and advanced age was associated with a higher extent of comprehensibility of the world. The latter supported the salutogenic assumption that psychological resources such as self-esteem and selfefficacy created life experiences that contributed to the individual's meaningful world. 


\section{Individuals' Social Support}

In general, studies on social support investigated individuals' resources from a variety of approaches such as contextual, emotional, and cognitive perspectives and also highlighted that the presence of others in stressful situations enhances one's mental health (see Srensen, Klungsyr, Kleiner, \& Klepp, 2011 for a review). Such studies focused on several dimensions of social support like the availability of support, irrespective of the extent of the support, provision of emotional support, information, tangible care, or material assistance from one's social network (Cohen, 2004). In examining the possible influence of social support on the development of SOC, Antonovsky and Sagy (1986) proposed that stable social support may reflect stable community and therefore may enhance the development of a stronger SOC.

Consequently, several studies have examined such assumptions. For example, data from research studies among children and adolescents emphasized the contribution of social support provided by classmates and teachers at school (Bowen, Richman, Brewster, \& Bowen, 1998; Natvig, Hanestad, \& Samdal, 2006), as well as from friends in the peer group (Evans, Marsh, \& Weigel, 2010; Marsh, Clinkinbeard, Thomas, \& Evans, 2007) for individuals' level of SOC. Similarly, these studies also demonstrated the role of aspects of neighborhood social support such as neighborhood social cohesion (Marsh et al., 2007; Nash, 2002).

Studies have also explored the possible role of social support among adults. For example, Volanen, Lahelma, Silventoinen, and Suominen (2004) reported that among men and women aged 25-64, the ability to receive social support and their satisfaction with this support contributed to the level of SOC among both sexes. At the same time, Volanen et al. (2004) raised the possibility of reciprocal relationships between these two variables suggesting that high level of social support may contribute to SOC and a strong SOC may help gain social relationships.

\section{Genetic Factors}

According to the salutogenic model, two major subgroups of variables are essential for the GRRs. First, major psychosocial GRRs extensively described previously and second genetic and constitutional GRRs (Antonovsky, 1979). For example, in exploring the psycholofical factors, in the late 1990s Cohen conducted a study among 74 women (mean age $35)$ where she examined which variables, sociological or personality factors, best explained the development of SOC (Cohen, 1997). The relationship between a narcissistic personality trait and the SOC was explored. The results showed that narcissistic elements made a more significant contribution to the SOC than the sociodemographic factors did. Here, especially items from the Narcissistic Personality Questionnaire linked to feelings of entitlement and self-satisfaction made the most significant contribution to SOC. A few years later, the question of the SOC as a state or personality trait was raised (Schnyder, Büchi, Sensky, \& Klaghofer, 2000). The main aim of this longitudinal study was to investigate the stability of the SOC over 6-12 months and how SOC was associated with depression and anxiety $(n=156)$. The results showed that SOC could be seen as a relatively stable trait. It was negatively associated with depression and anxiety. The authors concluded that SOC was not merely a proxy measure of psychopathology, but rather a partially independent, general measure of a person's world view.

This was in the late 1990s and early 2000s. Recent research exploring genetic factors was conducted on twins. However, research on the association between genetic factors and SOC is sparse. Hansson and colleagues (2008) conducted the Twin Mother's Study with the specific aim to explore individual resilience factors from a genetic perspective among 326 Swedish twin pairs (150 monozygotic and 176 dizygotic). The study was the first one to investigate how genes and the environment influence resiliency/ salutogenic factors. The results showed that nonshared environmental components were of principal importance in individual resiliency/salutogenic factors, but noted that genetic influences were important. They found that $35 \%$ of SOC was due to genetic effects and $57 \%$ was due to nonshared environmental effects (environmental differences between the twins). More recently published research confirmed the results of the Swedish Twin Mother's Study. Silventoinen and colleagues analyzed the effects of genetic and environmental factors on the SOC in young adulthood among 3193 Finnish twins (Silventoinen et al., 2014). The twins and their parents rated their emotional family environment independently when the twins were 12 years of age. The findings showed that genetic factors explained $39 \%$ of the variation of SOC in males and $49 \%$ in females. The rest of the variation was explained by environmental factors unique to each twin individually. For the dimensions of SOC, the highest genetic correlation was found between comprehensibility and manageability ( 0.90 in males and 0.97 in females). Taken together, these studies emphasize the possible role of genetic factors as well as environmental factors in understanding individual SOC. 


\section{Generalized Resistance Resources: The Family Level}

\section{Parental Resources}

As argued by many studies, parents' psychological resources as well as their developmental histories may influence the quality of their childrearing and, through parenting, child development outcomes (Arteche \& Murray, 2011; Belsky \& Pluess, 2012). Such studies investigated diverse parental personal resources including variables such as parents' psychopathology and well-being (Campbell, 2003; Goodman \& Gotlib, 2002), parents' personality (Belsky \& Barends, 2002), and parents' patterns of attachment (Mikulincer \& Shaver, 2007). In light of these studies' assumptions, the current section will review research studies focusing on the possible role of parental personal resources in understanding children's SOC.

For example, outcomes from Al-Yagon (2008) reported on the unique value of maternal level of SOC to her offspring's level of SOC. As suggested by this study, one may assume that mothers with high coherence levels, who tend to perceive stressful situations as less threatening and as more manageable, may provide their children with a more secure, consistent, and calm environment and may model effective strategies to cope with stressors as well. Similarly, Idan (2010) examined the role of parental SOC, hope, and family climate in explaining the coping resources, such as SOC, of high school students with severe and persistent LD, and reported that parental and family resources (parents' cohesion, SOC, hope, and effort) predicted their children's coping resources (children's cohesion, SOC, hope, and effort).

Research has also highlighted the contribution of fathers' emotional resources (i.e., attachment and affect) in explaining their offspring's SOC. For instance, Al-Yagon (2011) reported that among school-age children with SLD or with typical development, fathers' high positive affect and low level of avoidance in attachment relationships as reflected by a lower tendency to adopt attachmentdeactivating strategies (Mikulincer \& Shaver, 2004) contributed to children's high level of SOC.

In addition, studies on parental resources also investigated the possible influence of parenting style. For example, in a longitudinal study, Feldt, Kokko, Kinnunen, and Pulkkinen (2005) showed that parental childcenteredness, which refers to an accepting and emotionally warm parental attitude toward the child combined with parents' supervision, was the only adolescents' variable that contributed to these participants' high SOC in adulthood.
Together, these studies suggested that in order to provide optimal care and a more consistent and load balanced environment, which in turn might enhance children's level of SOC, parents must possess sufficient psychological and coping resources such as regulating impulses, taking others' perspectives, perceiving stressful situations as more manageable, and providing a model for effective coping with stressors (Belsky, 1984; Zahn-Waxler, Duggal, \& Gruber, 2002)

\section{Families' Demographic Resources}

In exploring the GRRs, research studies have also demonstrated the possible role of the family's demographic resources and characteristics. For instance, Ristkari, Sourander, Rønning, Nikolakaros, and Helenius (2008) reported that low level of parental education level, death and serious illness of parents, and parental divorce contributed to lower levels of SOC among young men. Thus, higher levels of parents' education (Feldt et al., 2005), higher economic status (Geckova, Tavel, van Dijk, Abel, \& Reijneveld, 2010), and living with both parents (Ayo-Yusuf, Reddy, \& Van Den Borne, 2009) contributed to higher level of SOC. Additionally, in accordance with the salutogenic framework assumptions on the GRRs (Antonovsky, 1979, 1987; Horsburgh \& Ferguson, 2012), studies exploring families' demographic resources have also shown the role of familial economic wealth as a general resistance resource that increases individuals' opportunities to have SOC-promoting experiences (García-Moya, Rivera, Moreno, Lindström, \& Jiménez-Iglesias, 2012).

\section{Family Climate Factors}

Several studies have highlighted the influential role of families' climate factors in SOC development across the lifespan. For example, in a study of elementary school children, Sharabi, Levi, and Margalit (2011) emphasized the possible role of family cohesion, one of two dimensions in Olson's (1986) Circumplex Model of family climate, on children's SOC. Findings revealed that children in cohesive families reported higher levels of SOC compared to children within noncohesive families.

Family climate factors have been found to contribute during the adolescent period as well. For instance, data from García-Moya and her colleagues (2012) demonstrated the role of family context as an important scenario in adolescents' SOC. This study yielded that among the family variables the following had a significant individual influence 
on SOC during adolescence, of which the most influential family dimensions were affection, ease of communication, and parental knowledge of their adolescents' life, such as their friends and leisure time activities. This study also demonstrated the contribution of the quality of relationships between the parents to adolescents' level of SOC. Similar results reported by Marsh and colleagues (2007) indicated the negative effect of parental high level of conflict in predicting levels of SOC in middle school youngsters. Furthermore, in an additional study on adolescents, GarciaMoya, Moreno, and Rivera (2014) reported that the quality of the relationships between parents and their children was the most influential factor in explaining adolescent SOC.

The importance of the family environment on the development of SOC was similarly demonstrated in Silventoinen and colleagues study (2014). The longitudinal study aimed to analyze genetic and environmental factors and their interaction affecting SOC among a large set of Finnish twins during young adulthood and during their home environment in childhood. The underlining assumption was based on evidence showing a strong genetic component behind psychological traits, such as personality and social attitudes (Bouchard \& McGue, 2003). The study's results emphasized the significance of a supportive childhood home on the development of a strong SOC in early adulthood. Genetic differences between individuals explained a third to one-half of the variation of SOC, especially in supportive family environments. Children who grew up in supportive family climates and experienced fewer emotional tensions with their parents demonstrated more genetic and less environmental variation in SOC in adulthood than children who were raised in emotionally less positive family climates.

Data from research on families from at risk populations also emphasized the role of family factors in explaining variation in SOC. The following review focuses first on families with special needs. For example, among families with children with Autism Spectrum Disorder (ASD), the severity of the disorders and their typically developing siblings' resources influenced the latter's SOC. Additionally, this study also demonstrated that among the group with high severity ASD symptoms, greater number of positive coping strategies buffered the typically developing siblings' SOC (Smith, Elder, Storch, \& Rowe, 2015). Significant coping strategies that were strongly associated with higher SOC included engaging in demanding activities, ventilating feelings, avoiding problems, and solving family problems. The strongest positive correlation was engaging in demanding activities, whereas ventilating feelings had a negative correlation suggesting that typically developing siblings who did not get angry or complain had lower SOC scores.

Other findings related to ASD compared the levels of SOC in parents of children with autism and parents of typically developing children and also examined the association between SOC levels and coping strategies. Pisula and Kossakowska (2010) found that parents raising children with ASD had a lower level of SOC compared to parents raising typically developing children. The SOC level of parents of children with ASD was positively correlated to seeking social support and self-controlling and negatively correlated with accepting responsibility and positive reappraisal. In the group of parents of children with ASD, positive correlations between distancing and total SOC, comprehensibility, and meaningfulness were revealed. The latter was perceived to indicate that having high levels of SOC orientation coincided with cognitive distancing from problems. These findings confirmed previous findings (Olsson \& Hwang, 2008) that parents of children with ASD had lower levels of SOC than parents of typically developing children and emphasized that the high level of stress related to the demands associated with raising a child with ASD had a negative effect on parental SOC (Mak, Ho, \& Law, 2007).

Moreover, Pisula and Kossakowska (2010) considered additional potential factors of lower SOC among parents of children with ASD. In line with Antonovsky's (1987) suggestion that SOC developed in childhood and early adolescence, stabilizing at early adulthood, they proposed that levels of SOC may fluctuate within life's circumstances and thus, difficult life experiences, such as raising a child with ASD, may affect the level of parental SOC.

Reviewing at risk families revealed several types of families, among which were those coping with traumatic life experiences, such as the Holocaust. Fossion and colleagues (2015) examined the consequences of extreme family functioning on resilience, SOC, anxiety, and depression. Results demonstrated that the children of Holocaust survivors' family types were more often damaged than in the general population. Growing in a damaged family impeded the development of coping strategies and enhanced the existence of depressive and anxiety disorders. In line with Fossion and colleagues' study (2014) on SOC and resilience in cases of multiple traumas, SOC was predicted to mediate between extreme families and the emergence of depressive and anxiety disorders. The recent study (Fossion et al., 2015) confirmed in a group of children of Holocaust survivors that which was found among Holocaust survivors: SOC mediated between family types and depressive and anxiety disorders.

Similarly, Zeidner and Aharoni-David (2014) found indirect effects of SOC in the relationship between memory traces of specific traumatic experiences of Holocaust survivors and adaptive outcomes. They concluded that the horrors of the Holocaust recruited the survivors' inner strengths and coping resources, which in turn contributed to the development of a stronger sense of meaning and coherence, improving a better sense of mental health. 


\section{Generalized Resistance Resources: The Community Level}

\section{School Setting}

Studies of school settings focused attention on the effect of the school setting features on SOC and its contribution as a mediating factor. Throughout the school years, students are faced with an array of increasingly difficult challenges related to their academic functioning. For instance, a study of the Norwegian education system (Natvig et al., 2006) explored elementary through junior high school children focusing on age and gender comparisons with regard to school-related stress and resources and their relations to the SOC construct. The sample consisted of 4116 school children aged 11,13 , and 15 years old. This study revealed that SOC was related to school-related characteristics, such as feeling pressured by schoolwork, social support from peers, and expectations. Sex and age variables played a significant role indicating that among the group of girls, the association between SOC and school-related characteristics was stronger among the youngest group.

In an attempt to explore the influence of school-related characteristics among youngsters with special needs, studies emphasized the prolonged academic challenges emerging from neurodevelopmental disabilities. As suggested by previous studies, these youngsters' difficulties at school remain a continuous source for increased stress, endless day-to-day struggling with age-appropriate academic roles, and with social and emotional challenges that in turn may contribute to their lower SOC (Idan, 2010; Idan \& Margalit, 2014; Lackaye \& Margalit, 2006).

As demonstrated by Idan's (2010) study, high levels of SOC were related to high levels of autonomy/competence, a subscale of the Basic Psychological Needs construct. In general, this construct refers to the individual's natural, innate, and constructive tendencies to develop a unified self. This tendency toward integration is characterized as involving both autonomy, tending toward inner organization and self- regulation, and homonymy, tending toward integration of oneself with others. Healthy development involves the complementary functioning of these two aspects (Deci \& Ryan, 2008). These inner resources, innate psychological needs, are the bases for integrating the differentiations of goal contents and regulatory processes. Should the needs-competence, autonomy, and relatedness-be satisfied, individuals will develop and function in healthy and optimal ways (Deci \& Ryan, 2000).

Idan's (2010) findings show that the highest levels of SOC and autonomy/competence were reported by females with SLD in a special high school compared to typically developing females and females with SLD from regular school classes. The highest levels of SOC and autonomy/ competence among adolescent males were reported by typically developing males. This parallelism between females with SLD in a special high school and typically developing males, and more interestingly, the females' high scores in levels of SOC and autonomy/competence may be explained by the females' belief that they had more control over their lives. Consequently, these females with SLD from the special school were able to better predict their internal and external environments, whether they be positively inclined or not. An additional explanation may lie in the possible role of the classification following diagnosis as SLD in selfevaluation, which in turn, may contribute to the level of SOC. Consequently, as suggested by Idan (2010), girls who had never had such a diagnosis lacked this so-called protection and bad grades may have been evidence that they were not smart enough to do well in school. On the other hand, boys who were diagnosed in the past with learning disabilities demonstrated declining levels of perceived intelligence regardless of their academic achievement. This may testify that boys may be more concerned with impersonal labeling removed from the classroom setting.

A prominent school-related feature is the role of the teacher as an extrafamilial significant other. In illustration of this, in a study focusing on the perception of teachers as a secure base among children with reading difficulties, Al-Yagon and Margalit (2006) revealed that children's reading difficulties affected their lower level of SOC. Children's perceptions of the teacher as a source of secure base were significantly related to high levels of SOC, emphasizing the possible protective role of extrafamilial figures who provide care and support in times of need.

Taking into account the above review of school-related characteristics, a scarcity of studies is apparent and calls for further exploration, examining in depth the variables that were presented in addition to a variety of other schoolrelated features that may shed light on the school community.

\section{Community Feature}

In an attempt to shift from the personal to the collective SOC, based on the understanding that an individual is part of a larger community, studies have explored possible features of communities that may contribute to collective SOC. Sense of community coherence (Peled, Sagy, \& BraunLewensohn, 2013) consists of the identical three components of the individual's SOC concept. Comprehensibility refers to the sense of predictability and security felt by the members of a community and the extent of which the community is comprehensible; manageability refers to the 
ability of the community to assist its members in times of need; and meaningfulness refers to the ability of the members of the community to express themselves in order to feel a higher level of satisfaction and interest within the community. Studies on community ecology revealed its role in predicting SOC development. Being a member of a minority group predicted lower SOC than being a member in a majority group (Braun-Lewensohn \& Sagy, 2011a, 2011b). Additionally, social support (Marsh et al., 2007) and neighborhood or community cohesion (García-Moya et al., 2013; Marsh et al., 2007; Peled et al., 2013) were contributing factors in the development of a strong SOC.

In this context of community features, prior studies have also investigated communities that cope with high and extreme levels of stress, such as political violence and war. For example, studies focusing on SOC and political violence revealed SOC as a mediator between exposure to missile attacks and stress-related reactions among adolescents (Braun-Lewensohn, Sagy, \& Roth, 2011) and as a mediator between attitudes toward war and peace within the IsraeliPalestinian conflict and anxiety reactions among adolescents living in a conflictual area (Braun-Lewensohn, Abu-Kaf, \& Sagy, 2015). Together, in both studies, strong SOC was related to higher resiliency and to lower levels of stressrelated reactions. In line with the assumption that peaceful ideas were correlated to stronger SOC (Pham, Vinck, \& Weinstein, 2010), outcomes from the study of BraunLewensohn and colleagues' (2015) suggested that adolescents who supported resolution of the PalestinianIsraeli conflict in peaceful ways had a stronger SOC and were less anxious. In contrast, those who supported more violent conflicts and war did not reveal this relationship. SOC acted as mediator between peace and war attitudes and anxiety solely for peaceful attitudes.

\section{Conclusions and Directions for Further Research and Interventions}

Together, the surveyed research studies emphasized the need for continued in-depth exploration of the possible role of different GRR-RDs for understanding individuals' SOC in different developmental phases across the lifespan, as well as through the individual, family, and community ecological levels. Furthermore, based on the expansion to community SOC, such in depth exploration regarding the GRR-RDs is required. Moreover, in examining the impact of GRR-RDs on individuals' and communities' levels of SOC, it seems important to reconsider the possible role of several main factors as follows.

\section{Reciprocal Relationship Between GRR-RDs and SOC}

As mentioned above the salutogenic theoretical framework proposed that over the lifespan, individuals may develop high levels of SOC through successful applications of GRR-RDs. At the same time, this theoretical framework also assumed a reciprocal and dynamic relationship between SOC and GRR-RDs. Consequently, whereas GRR-RDs may contribute to an individual's and community's levels of SOC, an individual's and community's levels of SOC may in turn contribute to mobilize GRRs for enhancing the ability of stress management (Antonovsky, 1987; Sagy \& Dotan, 2001). However, only few research studies reviewed in the present chapter examined this assumption on the reciprocal relationships between these two variables (e.g., Volanen et al., 2004), calling for future investigation regarding the possible bidirectionality of these interrelationships.

\section{Individuals' Differential Susceptibility to Environment Effects}

Previous studies have underscored that individuals may vary in their responsivity to the qualities of their environments, including their childrearing experiences (see Pluess \& Belsky, 2011 for a review). These assumptions are generally framed in diathesis-stress or "dual risk" terms, proposing that some individuals tend to be more vulnerable due to their biological/neurological and or behavioral characteristics (i.e., "stress" or "risk 1") to the adverse effects of negative experiences and environmental qualities (i.e., "diathesis" or "risk 2") (Belsky, BakermansKranenburg, \& van Ijzendoorn, 2007; Belsky \& Pluess, 2009; Trentacosta et al., 2008), whereas others may be relatively resilient to these negative factors. Findings from such studies have also pinpointed that individuals may vary not only in the degree to which they are vulnerable to the negative effects of adverse experiences but also, more generally, in their "developmental plasticity" (Boyce \& Ellis, 2005). Accordingly, this hypothesis which was termed the "biological sensitivity to context" (Boyce \& Ellis, 2005), or "differential susceptibility hypothesis" (Belsky, 2005), assumes that individuals may vary in their susceptibility to both adverse and beneficial effects of childrearing influences.

Overall, studies analyzing the susceptibility factors that may contribute to individual children's differential susceptibility emphasized the possible role of three categories of variables, such as genetic factors (e.g., short allele of the 
serotonin transporter linked polymorphic region, 5-HITTLPR), the physiological factors (e.g., cortisol reactivity), and behavioral factors (e.g., negative emotionality) (see Pluess \& Belsky, 2011 for a review). Such findings call for comprehensive additional exploration regarding individuals' variations in genetic, biological, and behavioral sensitivities, which may predict their susceptibility not only to the adverse effects of GRR-RDs, but also to beneficial effects of such factors. Such differential susceptibility has rarely been examined among communities, calling for future comprehensive investigation.

\section{Flexibility Versus Stability}

The current review raises an important question regarding the flexibility versus stability of SOC across the lifespan. Antonovsky (1987) hypothesized that SOC develops during childhood and stabilizes during the early adulthood stage. In contrast, other research proposed SOCs changes over an entire lifetime (e.g., Nilsson, Holmgren, Stegmayr, \& Westman, 2003; Nilsson, Leppert, Simonsson, \& Starrin, 2010). These findings raise several important issues regarding the longitudinal fluctuations as well as stability versus flexibility in individual SOC across the different development phases.

\section{Selected GRR-RDs}

Conceptual matters merit words of caution, regarding the possible role of GRR-RDs in understanding individuals' level of SOC. Inasmuch as these selected GRR-RDs reviewed in the current chapter are only few of the possible individual, familial, and community factors, additional resources should be considered. Such resources may include the individual's self-regulation and executive functioning abilities, parental monitoring levels, and parental anxiety, as well as school climate and collective versus individual approach.

\section{Clinical and Interventional Implications}

Acknowledging the importance of SOC as a factor contributing to effective coping with challenges and stressors and well-being, several intervention programs were developed in order to enhance SOC. These interventions highlight the factors that develop SOC throughout the lifespan and emphasize the flexibility of the construct and its potential influences (Janik \& Kroger, 2007; Kahonen, Naatanen, Tolvanen, \& Salmela-Aro, 2012; Mayer \& Boness, 2011; Pallasch \& Hameyer, 2008). The following provides examples of interventions promoting SOC in different contexts.

Within the school setting, Mayer and Boness (2011) proposed a didactic model (the team ombuds model) which aimed at promoting SOC and transcultural competencies in educational contexts. Based on studies demonstrating that teachers perceived educational approaches such as concepts of intercultural communication as enriching and stimulating, strengthening self-consciousness, self-worth, and SOC (Pallasch \& Hameyer, 2008), the model aimed at promoting GRRs of learners and teachers as well as at ameliorating comprehensibility, manageability, and meaningfulness. It was based on a vertical hierarchy of interacting social units in which learners created teams which were the basis of the educational process. The students who were in a position of trust worked closely with the teachers in resolving conflicts or improving interaction between the students and their teachers. This led to an increase in team competence and individual performance which decreased feelings of anxiety, dissatisfaction, and uncertainty (Janik \& Kroger, 2007). Thus, the learning input was acquired during team work (comprehensibility), team work was promoted (manageability), and students learned how to learn and set priorities according to their interests (meaningfulness).

Within an occupational context, Kahonen et al. (2012) reported on two group interventions (psychodramatic and analytic) promoting SOC in an occupational healthcare context. The psychodrama method was based on socio and psychodramatic techniques, such as drawing, music, and writing, and muscle relaxation and exercises using the imagination. The analytic method (Foulkes \& Anthony, 1990) was based on free flowing discussions in order to provide the participants with (1) a sense of security and belonging on the collective level, creating an atmosphere that enables expression of personal feelings; (2) an ability to discuss the feelings awakened by the group on a projective level; and (3) an awareness of one's inner world and its development in the complex relationship between past and present on the transference level. The action-based psychodrama group showed a higher increase in SOC than the dialog-based analytic group, while the improvement in the latter group was significant during the 6-month follow-up. The study concluded that due to its effectiveness, group intervention should be considered an important strategy alongside improvement in the organizational climate and second, that it was possible to enhance SOC by a relatively short group intervention among employees suffering burnout symptoms.

Open Access This chapter is distributed under the terms of the Creative Commons Attribution-Noncommercial 2.5 License (http:// creativecommons.org/licenses/by-nc/2.5/) which permits any noncommercial use, distribution, and reproduction in any medium, provided the original author(s) and source are credited. 
The images or other third party material in this chapter are included in the work's Creative Commons license, unless indicated otherwise in the credit line; if such material is not included in the work's Creative Commons license and the respective action is not permitted by statutory regulation, users will need to obtain permission from the license holder to duplicate, adapt or reproduce the material.

\section{References}

Ainsworth, M. D., \& Wittig, B. A. (1969). Attachment and exploratory behavior of one-year-olds in a strange situation. In B. M. Foss (Ed.), Determinants of infant behavior (Vol. 4, pp. 113-136). London: Methuen.

Allen, J. P. (2008). The attachment system in adolescence. In J. Cassidy \& P. R. Shaver (Eds.), Handbook of attachment: Theory, research, and clinical applications (pp. 419-435). New York: Guilford Press.

Al-Yagon, M. (2008). Maternal personal resources and children's socioemotional and behavioral adjustment. Child Psychiatry and Human Development, 30, 283-298.

Al-Yagon, M. (2010). Maternal emotional resources and socioemotional well-being of children with and without learning disabilities. Family Relations, 59, 152-169.

Al-Yagon, M. (2011). Fathers' emotional resources and children's socioemotional and behavioral adjustment among children with learning disabilities. Journal of Child and Family Studies, 20, 569-584.

Al-Yagon, M. (2014a). Child-mother and child-father attachment security: Security: Links to internalizing adjustment among children with learning disabilities. Child Psychiatry and Human Development, 45, 119-131.

Al-Yagon, M. (2014b). Fathers and mothers of children with learning disabilities: Links between emotional and coping resources. Learning Disability Quarterly, 38(2), 112-128. doi:10.1177/ 0731948713520556.

Al-Yagon, M., \& Margalit, M. (2006). Loneliness, SOC, and perception of teachers as a secure base among children with reading difficulties. European Journal of Special Needs Education, 21(1), 21-37.

Antonovsky, A. (1979). Health, stress and coping. San Francisco: Jossey-Bass.

Antonovsky, A. (1987). Unraveling the mystery of health. San Francisco: Jossey-Bass.

Antonovsky, A. (1991). The structural resources of salutogenic strengths. In C. L. Cooper \& R. Payne (Eds.), Personality and stress: Individual differences in the stress process. New York: Wiley.

Antonovsky, H., \& Sagy, S. (1986). The development of a sense of coherence and its impact on responses to stress situations. Journal of Social Psychology, 126, 213-225.

Arteche, A., \& Murray, L. (2011). Maternal affective disorder and children's representation of their families. Journal of Child and Family Studies, 20, 822-832.

Ayo-Yusuf, O. A., Reddy, P. S., \& Van Den Borne, B. W. (2009). Longitudinal association of adolescents' sense of coherence with tooth-brushing using an integrated behaviour change model. Community Dentistry and Oral Epidemiology, 37(1), 68-77.

Belsky, J. (1984). The determinants of parenting: A process model. Child Development, 55, 83-96.

Belsky, J. (2005). Differential susceptibility to rearing influences: An evolutionary hypothesis and some evidence. In B. Ellis \& D. B. Jorklund (Eds.), Origins of the social mind: Evolutionary psychology and child development (pp. 130-163). New York: Guildford.

Belsky, J., Bakermans-Kranenburg, M. J., \& van Ijzendoorn, M. H. (2007). For better and for worse: Differential susceptibility to environmental influences. Current Directions in Psychological Science, 16, 300-304.

Belsky, J., \& Barends, N. (2002). Personality and parenting. In M. H. Bornstein (Ed.), Handbook of parenting (2nd ed., Vol. 3, pp. 415-438). Mahwah, NJ: Lawrence Erlbaum.

Belsky, J., \& Pluess, M. (2009). The nature (and nurture?) of plasticity in early human development. Perspectives on Psychological Science, 4, 345-351.

Belsky, J., \& Pluess, M. (2012). Differential susceptibility to long-term effects of quality of child care on externalizing behavior in adolescence? International Journal of Behavioral Development, 36(1), $2-10$.

Bernier, A., \& Matte-Gagne, C. (2011). More bridges: Investigating the relevance of self-report and interview measures of adults' attachment for marital and caregiving relationships. International Journal of Behavioral Development, 35, 307-316.

Bouchard, T. J., \& McGue, M. (2003). Genetic and environmental influences on human psychological differences. Journal of Neurobiology, 54(1), 4-45.

Bowen, G. L., Richman, J. M., Brewster, A., \& Bowen, N. (1998). Sense of school coherence, perceptions of danger at school, and teacher support among youth at risk of school failure. Child and Adolescent Social Work Journal, 15, 273-286.

Bowlby, J. (1973). Attachment and loss: Anxiety, anger, and separation. New York: Basic Books.

Bowlby, J. (1982). Attachment and loss: Attachment. New York: Basic Books. (Original work published 1969).

Boyce, W. T., \& Ellis, B. J. (2005). Biological sensitivity to context: An evolutionary-developmental theory of the origins and functions of stress reactivity. Development and Psychopathology, 17, 271-301.

Braun-Lewensohn, O., Abu-Kaf, S., \& Sagy, S. (2015). Attitudes towards war and peace and their relations with anxiety reactions among adolescents living in a conflictual area. Journal of Youth Studies, 18(1), 68-69.

Braun-Lewensohn, O., \& Sagy, S. (2011a). Salutogenesis and culture: Personal and community sense of coherence among adolescents belonging to three different cultural groups. International Review of Psychiatry, 23(6), 533-541.

Braun-Lewensohn, O., \& Sagy, S. (2011b). Coping resources as explanatory factors of stress reactions during missile attacks: comparing Jewish and Arab adolescents in Israel. Community Mental Health Journal, 47(3), 300-310.

Braun-Lewensohn, O., Sagy, S., \& Roth, G. (2011). Adolescents under missile attacks: Sense of coherence as a mediator between exposure and stress related reactions. Journal of Adolescence, 34, 195-197.

Campbell, S. B. (2003). Behavior problems in preschool children: Clinical and developmental issues. New York: Guilford Press.

Cassidy, J., \& Shaver, P. R. (2008). Handbook of attachment: Theory, research, and clinical applications (2nd ed.). New York: Guilford Press.

Cohen, O. (1997). On the origins of a sense of coherence: Sociodemographic characteristics, or narcissism as a personality trait. Social Behavior and Personality, 25(1), 49-58.

Cohen, S. (2004). Social relationships and health. American Psychologist, 59, 676-684.

Collins, N. L., \& Ford, M. B. (2010). Responding to needs of others: The caregiving behavioral system in intimate relationships. Journal of Social and Personal Relationships, 27, 235-244.

Daoud, N., Polsky-Berger, A., Abu-Kaf, S., \& Sagy, S. (2015). Sense of coherence among women in polygamous and monogamous marriages. Manuscript in preparation.

Deci, E. L., \& Ryan, R. M. (2000). The what and why of goal pursuits: Human needs and the self-determination of behavior. Psychological Inquiry, 2(4), 227-268. 
Deci, E. L., \& Ryan, R. M. (2008). Facilitating optimal motivation and psychological well-being across life's domains. Canadian Psychology, 49(1), 14-23.

Evans, W. P., Marsh, S. C., \& Weigel, D. J. (2010). Promoting adolescent sense of coherence: Testing models of risk, protection, and resiliency. Journal of Community and Applied Social Psychology, 20, 30-43.

Feldt, T., Kokko, K., Kinnunen, U., \& Pulkkinen, L. (2005). The role of family background, school success, and career orientation in the development of sense of coherence. European Psychologist, 10 , 298-308.

Florian, V., Mikulincer, M., \& Bucholtz, I. (1995). Effects of adult attachment style on the perception and search for social support. Journal of Psychology, 129, 665-676.

Fossion, P., Leys, C., Kempenaers, C., Braun, S., Verbanck, P., \& Linkowski, P. (2014). Psychological and social-demographic data contributing to the resilience of Holocaust survivors. Journal of Psychology, 148(6), 641-657.

Fossion, P., Leys, C., Vandeleur, C., Kempenaers, C., Braun, S., Verbanck, P., et al. (2015). Transgenerational transmission of trauma in families of Holocaust survivors: He consequences of extreme family functioning on resilience, sense of coherence, anxiety and depression. Journal of Affective Disorders, 171, 48-53.

Foulkes, S. H., \& Anthony, E. J. (1990). Group psychotherapy. London: Karnac.

García-Moya, I., Moreno, C., \& Jiménez-Iglesias, A. (2013). Understanding the joint effects of family and other developmental contexts on the sense of coherence (SOC): a person-focused analysis using the Classification Tree. Journal of Adolescence, 36, 913-923.

Garcia-Moya, I., Moreno, C., \& Rivera, F. (2014). Obtaining a hierarchy of contextual factors in shaping the SOC of male and female adolescents. Journal of Happiness Studies, 15, 1267-1287.

García-Moya, I., Rivera, F., Moreno, C., Lindström, B., \& JiménezIglesias, A. (2012). Analysis of the importance of family in the development of sense of coherence during adolescence. Scandinavian Journal of Public Health, 40, 333-339.

Geckova, A. M., Tavel, P., van Dijk, J., Abel, T., \& Reijneveld, S. (2010). Factors associated with educational aspirations among adolescents: Cues to counteract socioeconomic differences? BMC Public Health, 10(1), 154.

Goodman, S. H., \& Gotlib, I. H. (2002). Children of depressed parents. Washington, DC: American Psychological Association.

Grossmann, K. E., Grossmann, K., \& Waters, E. (2006). Attachment from infancy to adulthood. New York: Guilford Press.

Hansson, K., Cederblad, M., Lichtenstein, P., Reiss, D., Pedersen, N., Belderhiser, J., et al. (2008). Individual resiliency factors from a genetic perspective: Results from a twin study. Family Process, 47 (4), 537-555.

Horsburgh, M. E., \& Ferguson, A. L. (2012). Salutogenesis: Origins of health and sense of coherence. In V. H. Rice (Ed.), Handbook of stress, coping, and health: Implications for nursing research, theory, and practice (2nd ed., pp. 180-198). Thousand Oaks, CA: Sage Publications, Inc.

Idan, O. (2010). Socio-emotional self-perceptions and family climate among students with learning disabilities in inclusive classes, typically achieving students from the same classes and students with severe learning disabilities in a special school and their hopeful thinking. Thesis submitted for the degree "Doctor of Philosophy", Joan and Jaime Constantiner School of Education, Tel Aviv University.

Idan, O., \& Margalit, M. (2014). Socio-emotional self-perceptions, family climate, and hopeful thinking among students with learning disabilities and typically achieving students from the same classes. Journal of Learning Disabilities, 47(2), 136-152.
Janik, S., \& Kroger, J. (2007). Das Team-Ombuds-Modell. Unpublished research paper, Padagogisches Seminar, Georg-AugustUniversitat, Gottingen.

Kahonen, K., Naatanen, P., Tolvanen, A., \& Salmela-Aro, K. (2012). Development of sense of coherence during two group interventions. Scandinavian Journal of Psychology, 53, 523-527.

Lackaye, T., \& Margalit, M. (2006). Comparisons of achievement, effort and self perceptions among students with learning disabilities and their peers from different achievement groups. Journal of Learning Disabilities, 39, 432-446.

Mak, W. W. S., Ho, A. H. Y., \& Law, R. W. (2007). Sense of coherence, parenting attitudes and stress among mothers of children with autism in Hong Kong. Journal of Applied Research in Intellectual Disabilities, 20, 157-167.

Marsh, S. C., Clinkinbeard, S. S., Thomas, R. M., \& Evans, W. P. (2007). Risk and protective factors predictive of sense of coherence during adolescence. Journal of Health Psychology, 12, 281-284.

Mayer, C.-H., \& Boness, C. (2011). Interventions to promoting sense of coherence and transcultural competences in educational contexts. International Review of Psychiatry, 23(6), 516-524.

Mikulincer, M., \& Shaver, P. R. (2004). Security-based selfrepresentations in adulthood: Contents and processes. In W. S. Rholes \& J. A. Simpson (Eds.), Adult attachment: Theory, research, and clinical implications (pp. 159-195). New York: Guilford Press.

Mikulincer, M., \& Shaver, P. R. (2005). Mental representations of attachment security: Theoretical foundation for a positive social psychology. In M. W. Baldwin (Ed.), Interpersonal cognition (pp. 233-266). New York: Guilford Press.

Mikulincer, M., \& Shaver, P. R. (2007). Attachment in adulthood: Structure, dynamics, and change. New York: Guilford Press.

Nash, J. K. (2002). Neighborhood effects on sense of school coherence and educational behavior in students at risk of school failure. Children and Schools, 24, 73-89.

Natvig, G. K., Hanestad, B. R., \& Samdal, O. (2006). The role of the student: Salutogenic or pathogenic? International Journal of Nursing Practice, 12, 280-287.

Nilsson, B., Holmgren, L., Stegmayr, B., \& Westman, G. (2003). Sense of coherence-Stability over time and relation to health, disease, and psychosocial changes in a general population. Scandinavian Journal of Public Health, 31, 297-304.

Nilsson, K. W., Leppert, J., Simonsson, B., \& Starrin, B. (2010). Sense of coherence and psychological well-being: Improvement with age. Journal of Epidemiol Community Health, 64, 347-352.

Olson, D. H. (1986). Circumplex model VII: Validation studies and FACES III. Family Process, 26, 337-351.

Olsson, M. B., \& Hwang, C. P. (2008). Socioeconomic and psychological variables as risk and protective factors for parental well-being in families of children with intellectual disabilities. Journal of Intellectual Disability Research, 52(12), 1102-1113.

Pallasch, W., \& Hameyer, U. (2008). Lerncoaching: Coaching to improve learning. Theoretical basics and practical examples. Weinheim: Juventa (German).

Peled, D., Sagy, S., \& Braun-Lewensohn, O. (2013). Community perception as coping resource among adolescents living under rockets fire: A salutogenic approach. Journal of Community Positive Practices, 4, 681-702.

Pham, P. N., Vinck, P., \& Weinstein, H. M. (2010). Human rights, transitional justice, public health and social reconstruction. Social Science \& Medicine, 70(1), 98-105.

Pisula, E., \& Kossakowska, Z. (2010). Sense of coherence and coping with stress among mothers and fathers of children with autism. Journal of Autism Development Disorder, 40, 1485-1494.

Pluess, M., \& Belsky, J. (2011). Prenatal programming of postnatal plasticity. Development and Psychopathology, 23, 29-38. 
Read, S., Aunola, K., Feldt, T., Leinonen, R., \& Ruoppila, I. (2005). The relationship between generalized resistance resources, sense of coherence, and health among Finnish people aged 65-69. European Psychologist, 10, 244-253.

Ristkari, T., Sourander, A., Rønning, J. A., Nikolakaros, G., \& Helenius, H. (2008). Life events, self-reported psychopathology and sense of coherence among young men-a population-based study. Nordic Journal of Psychiatry, 62, 464-471.

Sagy, S., \& Antonovsky, H. (1996). Structural sources of the sense of coherence: Two life stories of Holocaust survivors in Israel. Israel Journal of Medical Sciences, 32(3-4), 200-205.

Sagy, S., \& Antonovsky, H. (2000). The development of the sense of coherence: A retrospective study of early life experiences in the family. International Journal of Aging and Human Development, $51,155$.

Sagy, S., \& Dotan, N. (2001). Coping resources of maltreated children in the family: A salutogenic approach. Child Abuse \& Neglect, 25, 1463-1480.

Schnyder, U., Büchi, S., Sensky, T., \& Klaghofer, R. (2000). Antonovsky's sense of coherence: Trait or state? Psychotherapy and Psychosomatics, 69, 296-302.

Seiffge-Krenke, I., \& Beyers, W. (2005). Coping trajectories from adolescence to young adulthood: Links to attachment state of mind. Journal of Research on Adolescence, 15, 561-582.

Sharabi, A., Levi, U., \& Margalit, M. (2011). Children's loneliness, sense of coherence, family climate and hope: Developmental risk and protective factors. The Journal of Psychology, 146(1-2), 61-83.

Silventoinen, K., Volanen, S.-M., Vuoksimaa, E., Rose, R. J., Suominen, S., \& Kaprio, J. (2014). A supportive family environment in childhood enhances the level and heritability of sense of coherence in early childhood. Social Psychiatry and Psychiatric Epidemiology, 49(12), 1951-1960.
Smith, L. O., Elder, J. H., Storch, E. A., \& Rowe, M. A. (2015). Predictors of sense of coherence in typically developing adolescent siblings of individuals with autism spectrum disorder. Journal of Intellectual Disability Research, 59(1), 26-38.

Srensen, T., Klungsyr, O., Kleiner, R., \& Klepp, O. M. (2011). Social support and sense of coherence: independent, shared and interaction relationships with life stress and mental health. International Journal of Mental Health Promotion, 13, 27-44.

Trentacosta, C. J., Hyde, L. W., Shaw, D. S., Dishion, T. J., Gardner, F., $\&$ Wilson, M. (2008). The relations among cumulative risk, parenting, and behavior problems during early childhood. Journal of Child Psychology and Psychiatry, 49, 1211-1219.

Volanen, S. M., Lahelma, E., Silventoinen, K., \& Suominen, S. (2004). Factors contributing to sense of coherence among men and women. European Journal of Public Health, 14, 322-330.

Waters, E., \& Cummings, E. (2000). A secure base from which to explore close relationships. Child Development, 71, 164-172.

Weismann, U., \& Hannoch, H.-J. (2011). Salutogenic perspectives on health maintenance: The role of resistance resources and meaningfulness. Geropsychology, 24(3), 127-135.

Ying, Y.-W., Lee, P. A., \& Tsai, J. L. (2007). Attachment, sense of coherence, and mental health among Chinese American college students: Variation by migration status. International Journal of Intercultural Relations, 31, 531-544.

Zahn-Waxler, C., Duggal, S., \& Gruber, R. (2002). Parental psychopathology. In M. H. Bornstein (Ed.), Handbook of parenting (2nd ed., Vol. 4, pp. 295-327). Mahwah, NJ: Lawrence Erlbaum.

Zeidner, M., \& Aharoni-David, E. (2014). Memories of Holocaust related traumatic experiences, sense of coherence, and survivors' subjective well-being in late life: Some puzzling findings. Anxiety, Stress, \& Coping, 28(3), 254-271. doi:10.1080/10615806.2014. 954244. 